\title{
Screening of Antimicrobial and Adhesive Activity of Lactobacilli Isolated from the National Food Products from Different Districts of the Karaganda Region (Kazakhstan)
}

\author{
Zhanerke Amirkhanova $^{1 *}(\mathbb{D})$, Saule Akhmetova ${ }^{2}$ (D) Samat Kozhakhmetov $^{3,4}$ (D), Almagul Kushugulova ${ }^{3}$, Rahat Bodeeva ${ }^{1}$, \\ Zauresh Issina ${ }^{5}$, Marat Tusbayev ${ }^{5}$ (D) \\ ${ }^{1}$ Department of Physiology, Buketov Karaganda University, Karaganda, Kazakhstan; ${ }^{2}$ Department of Biomedicine, Karaganda \\ Medical University, Karaganda, Kazakhstan; ' ${ }^{3}$ aboratory of Human Microbiome and Longevity "National Laboratory Astana", \\ Nazarbayev University, Nur-Sultan, Kazakhstan; ${ }^{4}$ Innovative Center ArtScience, Nur-Sultan, Kazakhstan; ${ }^{5}$ School of Dentistry, \\ Karaganda Medical University, Karaganda, Kazakhstan
}

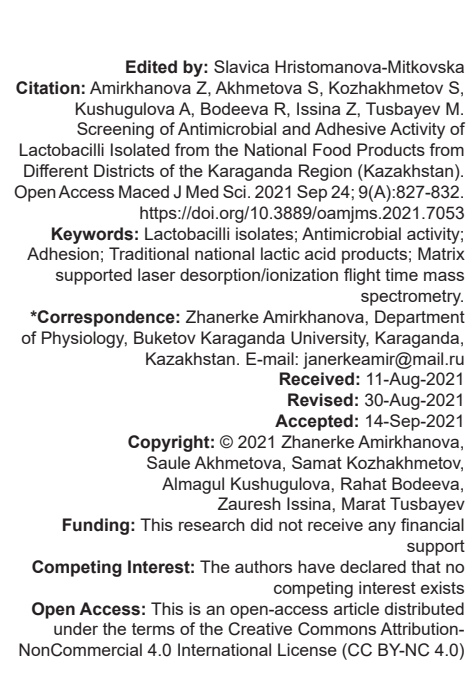

Introduction

The nutritional peculiarities of the population of Kazakhstan have a long history of traditional lactic acid products from milk of cows, mares, camels, and goats and are based on milk fermentation [1]. To date, the study of probiotic strains with highly active biological properties isolated from local Kazakh lactic acid products with a long history is of high priority [2]. Due to the variability of opportunistic bacteria manifested and an increase in antibiotic resistance [3], [4], a problem of food safety is particularly rampant as for the preservation of food by suppressing other microorganisms causing foodborne illness or food spoilage [3], [5], as well as changes in the biological properties of probiotic crops

\begin{abstract}
BACKGROUND: It is a national priority to look for new probiotic bacteria with highly active biological properties to create a new generation of probiotics, ferments, therapeutic, and prophylactic fermented milk products, taking into AIM: The aim of the study is to assess probiotic properties of strains of lactobacilli (antimicrobial and adhesive) which are isolated from national lactic acid products from different districts of the Karaganda region (Kazakhstan) To determine the morpho-cultural properties, the following methods were used: Gram staining, a catalase test serial dilutions. The Matrix Supported Laser Desorption/lonization Flight Time Mass Spectrometry was used for

RESULTS: In this experiment, 26 lactobacillus isolates were isolated from 68 samples of national lactic acid products produced in a traditional homemade way in different districts of the Karaganda region (Kazakhstan). As a result of the studies carried out on the cultural and morphological characteristics and identification by the mass spectrometer, the following lactobacilli were obtained: Lactobacillus acidophilus (two strains), Lactobacillus delbrueckii subsp. bulgaricum (two strains), Lactobacillus rhamnosus (seven strains), Lactobacillus plantarum (two strains), Lactobacillus paracase , and Lactobacillus fermentum (two strains). Twenty-six isolates of lactobacilli were tested for antimicrobial activity, 13 isolates of which showed an inhibitory effect, but the degree of antagonism varied among lactobacillus isolates. In general, the inhibitory activity of lactobacillus isolates was shown against the Gram-negative indicato microorganisms Salmonella typhimurium NCTC 12023, Escherichia coli NCTC 12923 . The antibacterial activity was
shown against the Staphylococcus aureus NCTC 12973 indicator microorganism in nine isolates of lactobacilli. Only six isolates of lactobacilli showed antifungal activity against the test strain of Candida albicans NCPF 3179. Out of 13

CONCLUSION: The obtained isolates from traditional dairy products are considered to be promising candidates and competitive isolates with some probiotic potential. This study calls for further researches to be made in this area.
\end{abstract}

during long-term storage as industrial crops in dairy industries [6]. The foregoing necessitates the search for new unique candidates for probiotics, in particular those with high antagonistic (capable of synthesizing metabolites with antimicrobial action with the generally recognized as safe status) adhesive properties.

The progress of the sciences engaged in studying microbiota confirms the nature of these microbes as a protective microflora with an expressed antagonistic activity against putrefactive and pyogenic opportunistic and pathogenic microorganisms.

Lactobacilli, being the representatives of the normal microbiota of the mucous membrane of humans and animals, play a key role in forming colonization resistance, which is one of the most important factors of 
the body's anti-infectious defense system in improving the microbial balance. This prompted us to conduct this study, namely, the interest in the peculiarities of lactobacilli and their metabolites as the main components of starter cultures, being the most widely used microorganisms as probiotics.

The given study was carried out to assess the probiotic properties (antimicrobial and adhesive) of lactobacillus isolates isolated from national lactic acid products from different districts of the Karaganda region (Kazakhstan).

\section{Methods}

\section{Materials}

Sixty-eight samples of national lactic acid products were used for this research (Table 1). All of them were home-made in a traditional way and taken from different districts of the Karaganda region (Kazakhstan).

Table 1: National lactic acid products and number of samples from the regions

\begin{tabular}{llllllll}
\hline Districts & \multicolumn{7}{l}{ National lactic acid products (number of samples) } \\
\cline { 2 - 8 } & Ayran & Koumiss & Ashigan kozhe & Kurt & Suzbe & $\begin{array}{l}\text { Cottage } \\
\text { cheese }\end{array}$ & Brynza \\
\hline Aktogay & 2 & 3 & 2 & 4 & 3 & 3 & - \\
Bukhar-Zhyrausky & - & 2 & - & 2 & 2 & 2 & 2 \\
Zhanaarkinsky & 2 & 5 & - & - & - & - & - \\
Karkaralinsky & 3 & 4 & 2 & 3 & 2 & 3 & - \\
Osakarovsky & - & 1 & - & 2 & - & 3 & 4 \\
Shetsky & - & - & - & 3 & 2 & 2 & - \\
Total & 68 & & & & & & \\
\hline
\end{tabular}

\section{Isolation and identification of lactobacilli isolates}

The lactobacillus isolates were isolated from national lactic acid products by the standard plate method [7].

The serial dilutions were prepared from each product in sterile solution followed by MRS agar-based inoculation (deMan, Rogosa, Sharpe), which had been cultivated at $37^{\circ} \mathrm{C}$ for 2 days under anaerobic conditions.

After incubation, the isolated colonies were tested by conducting Gram stain and catalase tests. The rod-shaped, Gram-positive, and catalase-negative isolates were selected for the tests. Following that, some individual colonies were subcultured in the MRS broth for $48 \pm 2 \mathrm{~h}$ at $+37^{\circ} \mathrm{C}$ with a couple of control smears taken. The selected strains were stored in the MRS broth containing $20 \%$ glycerol and stored at $-22^{\circ} \mathrm{C}$ for further analysis. Before each analysis, the isolates were activated in the MRS broth.

The pure cultures of lactobacilli were identified using Matrix Supported Laser Desorption/lonization Flight Time Mass Spectrometry (MALDI-TOF MS) (MALDI-TOF MS, Bruker, Germany). The bacterial spectra were compared with the MALDI-TOF MS biotype reference library [8].

The identification reliability criteria were applied by the following score values:

2.300-3.000 - highly probable identification of species; 2.000-2.299 - reliable identification of genus and probable identification of species; 1.700-1.999 - probable identification of genus; and 0-1.699 identification failed.

\section{Antimicrobial properties of lactobacilli isolates against indicator microorganisms}

The study of the bactericidal and antifungal activity of antagonist strains in relation to test strains to opportunistic microorganisms of various groups was determined by the deferred-antagonism method [9].

The antimicrobial activity of the obtained isolates of lactobacilli was assessed using indicator microorganisms: Staphylococcus aureus NCTC 12973, Escherichia coli NCTC 12923, Salmonella typhimurium NCTC 12023, Candida albicans NCPF 3179 (the test strains from Laboratory of Human Microbiome and Longevity "National Laboratory Astana," Nazarbayev University (the city of Nur-Sultan, Kazakhstan).

The antimicrobial activity was assessed by no growth area of test strains around the colony of the tested isolates of lactobacilli. The studies were repeated 3 times with the results expressed as the arithmetic mean.

\section{Adhesive activity of lactobacilli isolates}

Buccal epithelial cells of a human were placed in a $7.2 \mathrm{pH}$ phosphate buffer. These cells were washed 3 times by centrifugation (at $1000 \mathrm{rpm}$ for $5 \mathrm{~min}$ ). The control smears were prepared from the sediment. A sample was considered suitable for the research if at least 2-3 epithelial cells were found in each field of view during microscopy.

To study the adhesive activity, $800 \mu \mathrm{l}$ of buccal cells' suspension and $600 \mu$ of lactobacilli's strain suspension at the concentration of $10^{5} \mathrm{CFU} / \mathrm{ml}$ were added to a centrifuge tube. The contents of the tubes were incubated for $2 \mathrm{~h}$ at $37^{\circ} \mathrm{C}$ with intermittent stirring. After incubation, non-adsorbed lactobacilli were removed by washing them twice by centrifugation (at $1000 \mathrm{rpm}$ for $3 \mathrm{~min}$ ). The sediment was stained with gentian violet, microscoped, and the number of attached lactobacilli was counted [10], [11].

The result was expressed as the arithmetic mean of the number of lactobacilli attached to one buccal cell. The intensity of adhesive activity was assessed: Non-adhesive strains $=0$; weakly adhesive $=1-5 ;$ medium adhesive $=5-10 ;$ and highly adhesive $=$ above 10 [12] . 


\section{Statistical analysis}

The obtained results of antimicrobial and adhesive activity are presented as mean \pm standard error, obtained as a result of three-fold repetition of the experiment (Statistica 8.0 software was used) [13], [14].

\section{Results}

\section{Morpho-cultural properties and identification of obtained isolates of lactobacilli}

In total, 26 isolates of lactobacilli were selected from the national lactic acid products, which were traditionally homemade and taken from different districts of the Karaganda region. The studies carried out on morphological characters indicate their belonging to the genus of Lactobacillus, Lacticaseibacillus, Lactiplantibacillus, and Limosilactobacillus [15].

All isolated strains are Gram-positive with the cells located: Singly, in pairs, in the form of a chain, motionless, no spores are formed (Figure 1a-c), catalase-negative (lactobacilli do not have catalase; therefore, no gas formation was observed in the sample with hydrogen peroxide).

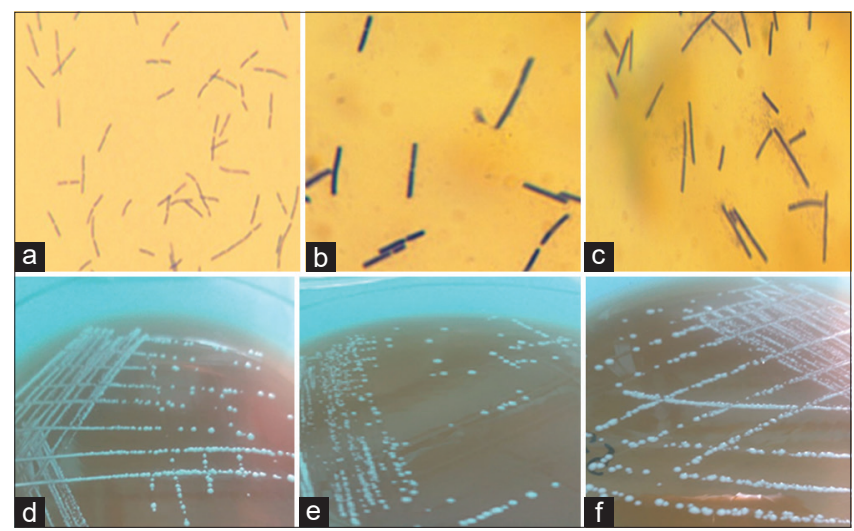

Figure 1: Microscopic image $(\times 100)$ and MRS agar-based colony's morphology of isolated lactic acid bacillus isolates. (a), (d) L. paracase isolates isolated from suzbe - 28; (b), (e) L. fermentum isolates isolated from ashigan kozhe -18; (c), (f) L. acidophilus isolates isolated from koumiss -52

The morphology of the colony of the isolated MRS agar-based isolates (Figure 1d-f) demonstrates white small, medium, convex with smooth edges, 1-3 $\mathrm{mm}$ in diameter, unpigmented ones, which grow well at $37^{\circ} \mathrm{C}$ for $48 \mathrm{~h}$ under anaerobic conditions.

In general, the lactic acid bacteria are identified in lactic acid products based on phenotypic, physiological, and biochemical criteria. However, these complex and laborious methods can underestimate the microbiological diversity of the food ecosystem [16].

The MALDI-TOF MS identification is a time efficient, economical, and reliable method [17]. The given studies have shown that the use of
MALDI-TOF-MS analysis has become part of the daily practical work of a microbiologist to identify lactobacilli, and even surpasses the previously used (classical) methods of microbiological identification in terms of speed and reliability.

As a result, the mass spectrometer identified the following in the presented samples: Lactobacillus acidophilus (two strains), Lactobacillus delbrueckil subsp. bulgaricum (two strains), Lactobacillus rhamnosus (seven strains), Lactobacillus plantarum (two strains), Lactobacillus paracasei (11 strains), and Lactobacillus fermentum (two strains).

In accordance with the score values, the results indicate the following accuracy of identification: (2.3003.000 ) - in 11 strains; (2.000-2.299) - in 12 strains; $(1.700-1.999)$ - in three strains.

\section{Screening for antagonistic activity of lactobacilli isolates}

Lactobacilli are known for their production of various antimicrobial compounds [18]. Microbial pathogens such as $S$. aureus, E. coli, S. typhimurium, and $C$. albicans in food items can cause spoilage and contribute to both foodborne diseases, drug resistance, and resistance to disinfectants [19].

In this regard, to determine the probiotic properties, all 26 isolated lactobacillus isolates were tested for antimicrobial activity against Gram-positive, Gram-negative, and yeast indicator microorganisms. Thirteen isolates had an inhibitory effect (Table 2 and Figure 2), but the degree of antagonism varied among these isolates.

Table 2: Antibacterial and antifungal activity of isolated isolates

\begin{tabular}{|c|c|c|c|c|}
\hline \multirow{2}{*}{$\begin{array}{l}\text { Symbols used to indicate } \\
\text { isolated lactobacillus } \\
\text { isolates }\end{array}$} & $\begin{array}{l}\text { S. aureus } \\
\text { NCTC } 12973\end{array}$ & $\begin{array}{l}\text { E. coli } \\
\text { NCTC } 12923\end{array}$ & $\begin{array}{l}\text { S. typhimurium } \\
\text { NCTC } 12023\end{array}$ & $\begin{array}{l}\text { C. albicans } \\
\text { NCPF } 3179\end{array}$ \\
\hline & \multicolumn{4}{|c|}{ Inhibition zones (diameter in mm) } \\
\hline L. rhamnosus $1 \ni$ & - & $10.0 \pm 2.0$ & $13.0 \pm 4.0$ & $7.0 \pm 2.0$ \\
\hline L. rhamnosus $2 э$ & - & - & $16.0 \pm 3.2$ & - $\quad$ \\
\hline L. rhamnosus $3 \ni$ & - & - & $14.0 \pm 3.6$ & $5.0 \pm 2.0$ \\
\hline L. rhamnosus $1 / 1$ & $15.0 \pm 1.0$ & $7.0 \pm 1.5$ & $10.0 \pm 0.5$ & $5.0 \pm 0$ \\
\hline L. plantarum 2/1 & $7.0 \pm 2.0$ & - & $14.0 \pm 1.0$ & $4.0 \pm 1.5$ \\
\hline L. paracasei 28 & $8.0 \pm 1.0$ & $6.0 \pm 2.3$ & $9.0 \pm 2.0$ & - \\
\hline L. paracasei 32 & $9.0 \pm 1.0$ & $10.0 \pm 1.0$ & $5.0 \pm 1.0$ & - \\
\hline L. paracasei 34 & $9.0 \pm 1.5$ & $11.0 \pm 1.5$ & $9.0 \pm 0$ & - \\
\hline L. paracasei 38 & $4.0 \pm 1.0$ & - & $4.0 \pm 1.0$ & $3.0 \pm 4.0$ \\
\hline L. fermentum 38/1 & $10.0 \pm 1.1$ & $9.0 \pm 1.0$ & $13.0 \pm 0.5$ & $3.0 \pm 0$ \\
\hline L. rhamnosus 39 & $13.0 \pm 2.0$ & $10.0 \pm 0$ & $10.0 \pm 0.5$ & - \\
\hline L. rhamnosus 40 & - & $9.0 \pm 0$ & $7.0 \pm 0$ & - \\
\hline L. rhamnosus- 52 & $7.0 \pm 0.5$ & $3.0 \pm 0$ & $7.0 \pm 1.2$ & - \\
\hline
\end{tabular}

The diameters of inhibition zones (in $\mathrm{mm}$ ) are presented as mean $+S .0 \pm$, the research is repeated 3 times. S. aureus: Staphylococcus aureus, E. coli: Escherichia colis $S$ typhimurium: Salmonella typhimurium, S. aureus. Staphylococcus aureus, E. coll. Eschenichia colli, S. typhimunium. Salmonella typhimurium, C. albicans: Candida albicans, L. E. comnosus. Lactobacilus mamnosus, L. plantarum: Lactobacillus plantarum, L. paracasei: Lactobacillus paracasei, L. fermentum: Lactobacillus fermentum, L. acidophilu:

The antibacterial activity against the indicator microorganism S. aureus NCTC 12973 was shown in nine isolates (the diameter of the retention zone varied, the lowest activity at $4 \mathrm{~mm}$, and the high activity at $15 \mathrm{~mm})$.

The antibacterial activity against E. coli NCTC 12923 was shown in nine isolates (the diameter of the retention zone varied from 10 to $16 \mathrm{~mm}$ ). 


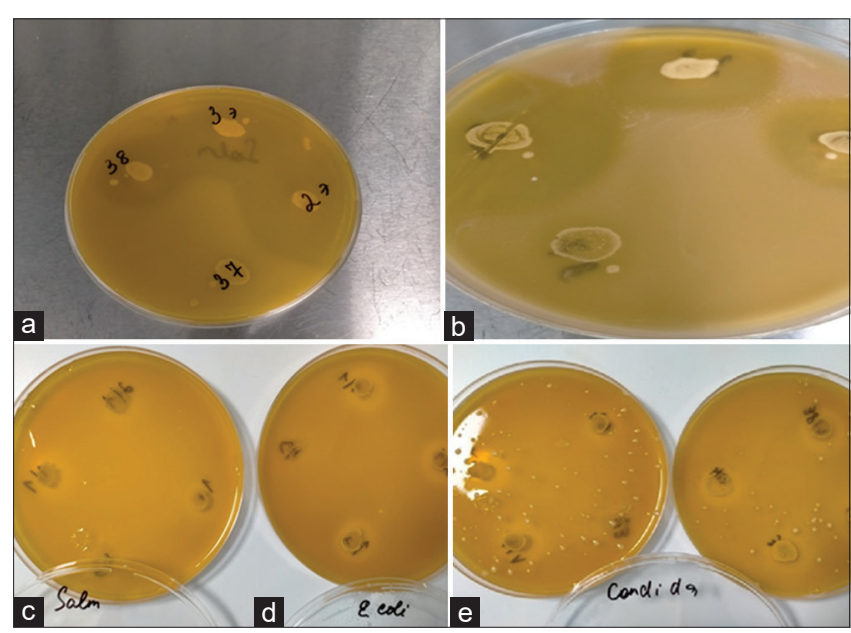

Figure 2: Inhibitory effect of isolated lactobacillus isolates to the following indicator microorganisms $S$. typhimurium NCTC 12023 (a), (c), S. aureus NCTC 12973 (b), E. coli NCTC 12923 (d), C. albicans NCPF 3179 (e)

The antibacterial activity against the ratio of $S$. typhimurium NCTC 12023 was detected in 13 isolates (the diameter of the retention zone varied with the lowest activity at $5 \mathrm{~mm}$, and the highest activity at $16 \mathrm{~mm}$ ).

Six strains of lactobacilli demonstrated antifungal activity against C. albicans NCPF 3179, the diameter of the retention zone varied from 3 to $7 \mathrm{~mm}$.

The spectrum of antimicrobial activity of lactobacilli (L. rhamnosus, L. plantarum, Lactobacillus casei, L. paracasei, L. acidophilus, L. fermentum, and Lactobacillus buchneri) metabolites is directed against shigella, salmonella, clostridia, pseudomonads, staphylococci, streptococci, listeria, and some types of fungi [19], [20], [21], [22], [23], [24].

Thus, we have not found any dependence between manifestation of antimicrobial and antifungal activity of the isolated strains and a particular genus, species and subspecies of lactobacilli, inhibiting antimicrobial and antifungal action, which is a strainspecific property. This conclusion is consistent with the data presented by other researchers [25].

\section{Adhesive activity of lactobacilli isolates}

Adhesive activity allows a microbial cell to adapt to adverse environmental impacts and increase its population. Thus, adhesive capacity can be considered as a standard biomarker when selecting a potential probiotic [26].

In the present study, we have evaluated 13 probiotic strains of lactobacilli with antimicrobial activity for their ability to adhere to buccal cells.

In the course of these studies, it has been found that the adhesive ability to the buccal epithelial cells of 13 lactobacillus isolates under investigation have the following adhesive ability: High (6), medium (3), and low (4) (Figure 3).

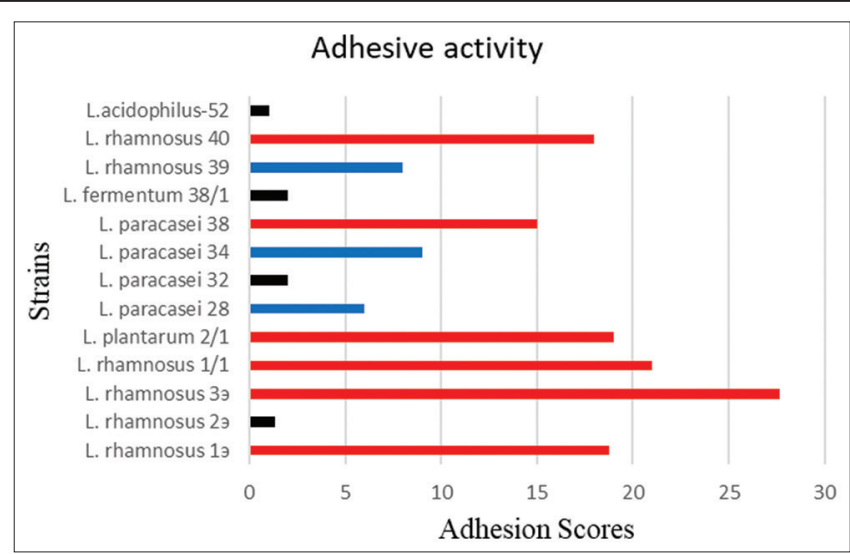

Figure 3: The number of lactobacillus isolates attached to one buccal cell: Up to 30 adhered bacterial cells - 1 point, 31 to $60-2$ points, 61 to $90-3$ points, 91 to $120-4$ points, more than $121-5$ points

The actual majority of the lactobacillus cell strains adheres to buccal epithelial cells and provides colonization. The highest adhesive activity was found in the isolates of L. rhamnosus $40, L$. paracasei 38 , L. plantarum $2 / 1$, L. rhamnosus $1 / 1$, L. rhamnosus $3 e$, and $L$. rhamnosus $1 e$.

The average adhesive activity is observed in the isolates of L. rhamnosus $39, L$. paracasei 34 , and L. paracasei 28.

The low adhesive activity is observed in the L. acidophilus-52, L. fermentum 38/1, L. paracasei 32, and $L$. rhamnosus $2 e$ strains.

The differences observed in the adhesion capacity of lactobacilli strains suggest that this trait varies among probiotic strains. This conclusion is completely consistent with other researchers who also reported the ability of probiotics to adhere in the cell being highly dependent on the strain, species, and genus [24]

\section{Discussion}

In this study, 26 lactobacillus isolates were isolated from 68 samples of national lactic acid products, which were home-made in a traditional way and were taken from different districts of the Karaganda region (Kazakhstan).

As a result of these studies, which were carried out on the cultural and morphological characteristics, the mass spectrometer identified the following strains: L. acidophilus (2 strains), L. delbrueckii subsp. bulgaricum (2 strains), L. rhamnosus (7 strains), L. plantarum (2 strains), L. paracasei (11 strains), and L. fermentum (2 strains).

The antimicrobial activity against pathogens is an important attribute to consider when selecting potential probiotic strains to maintain a healthy microbial balance in the gastrointestinal tract [25]. 
They are able to produce substances with antibiotic activity in the process of their growth and development, the resulting antibiotic substance ensures the dominance of lactobacilli and suppression of opportunistic pathogenic microflora. Therefore, the use of lactobacilli with expressed antagonistic activity is of practical importance [27].

In the present study, 26 lactobacillus isolates were tested for antimicrobial activity. Thirteen isolates of which showed an inhibitory effect, but the degree of antagonism varied among lactobacillus isolates.

Basically, the inhibitory activity of lactobacillus isolates was shown against the Gram-negative indicator microorganisms S. typhimurium NCTC 12023, E. coli NCTC 12923, and S. aureus NCTC 12973. 9 lactobacillus isolates demonstrated some antibacterial activity.

The antifungal activity against the $C$. albicans NCPF 3179 test strain was detected only in six lactobacillus isolates. It is believed that this could be due to the high productivity of candida lysozyme, which acts as a protective factor.

Furthermore, 13 isolates of lactobacilli were additionally tested for adhesive activity in vitro.

The in vitro studies with various intestinal cell lines and mucin (high molecular weight glycoproteins containing acidic polysaccharides, are produced by epithelial cells of all animals and humans) have been widely used over the past decades to assess the adhesion capacity of probiotic bacteria.

The adhesive capacity of probiotic lactobacilli is usually studied in vitro. The most widely used models for assessing the adhesion of microorganisms are culture tissue's cells. To study the adhesion to intestinal epithelial cells, in particular, Caco-2, HT-29 cells, and mucus secreting HT-29 MTX cells [28], [29], [30], [31] are usually used.

The majority of probiotic foods are consumed orally, thus, it is possible that bacteria in these foods can also attach to the surfaces of the oral cavity [11].

In this regard, to study the adhesive properties, buccal epithelial cells were used. In this experiment, L. rhamnosus $40, L$. paracasei $38, L$. plantarum $2 / 1$, L. rhamnosus $1 / 1$, L. rhamnosus $3 e$, L. rhamnosus 1e, L. rhamnosus 39, L. paracasei 34, and L. paracasei 28 isolates competed for binding to buccal epithelial cells.

The obtained results confirmed the experimental data that 13 selected isolates of lactobacilli have antimicrobial activity, while nine isolates showed medium and high adhesive activity. The experiment showed that the lactobacillus isolates were promising probiotics, taking into account their probiotic data, namely, antimicrobial (the effect of resisting the opportunistic flora) and adhesive activity (the phenomenon of adhesion).

\section{Conclusions}

The isolated strains from traditional dairy products are promising candidates and competitive isolates with probiotic potential properties. They can play an important role in the food industry as starter cultures, cocultures or bioprotective crops to improve food quality and safety, or as probiotic therapeutic agents suitable for clinical practice.

\section{References}

1. Aitzhanova AA, Oleinikova EA, Saubenova MG, Daugalieva ST, Berzhanova RZ. Selection of antagonistically active strains of lactic acid bacteria from milk of various animal species. Exp Biol. 2020;2(83):72-8. https://doi.org/10.26577//eb.2020.v83. i2.08

2. Kushugulova A, Kozhakhmetov S, Supiyev A, Shakhabayeva G Saduakhasova S, Sabitkyzy $\mathrm{S}$, et al. Isolation and characterization of lactobacilli from traditional Kazakh dairy products. Int J Probiotics. 2013;8(2-3):95-9.

3. Ghosh C, Sarkar P, Issa R, Haldar J. Alternatives of conventional antibiotics in the era of antimicrobial resistance. Trends Microbiol. 2019;27(4):323-38. https://doi.org/10.1016/j. tim.2018.12.010

PMid:30683453

4. Zeng $\mathrm{Y}$, Li $\mathrm{Y}, \mathrm{Wu} \mathrm{QP}$, Zhang JM, Xie XQ, Ding $\mathrm{Y}$, et al Evaluation of the antibacterial activity and probiotic potential of Lactobacillus plantarum Isolated from Chinese Homemade Pickles. Can J Infect Dis Med Microbiol. 2020;2020:8818989. https://doi.org/10.1155/2020/8818989

5. Kushugulova A, Löber U, Akpanova S, Rysbekov K, Kozhakhmetov S, Khassenbekova Z, et al. Dynamic changes in microbiome composition following mare's milk intake for prevention of collateral antibiotic effect. Front Cell Infect Microbiol. 2021:11:622735. https://doi.org/10.3389/ fcimb.2021.622735

PMid:33968795

6. Nemska V, Karsheva M, Danova S, Georgieva N. Microbiological, physico-chemical and rheological evaluation of yoghurts, fermented with lactobacilli from traditional Bulgarian dairy products. J Chem Technol Metal. 2021;56(3):526-32.

7. Wang D, Liu W, Ren Y, De L, Zhang D, Yang Y, et al. Isolation and identification of lactic acid bacteria from traditional dairy products in Baotou and Bayannur of Midwestern Inner Mongolia and q-PCR Analysis of Predominant. Korean J Food Sci Anim Resour. 2016;36(4):499-507. https://doi.org/10.5851/ kosfa.2016.36.4.499

PMid:27621691

8. Alatoom AA, Cunningham SA, Ihde SM, Mandrekar JN, Patel R Comparison of direct colony method versus extraction method for identification of gram-positive cocci by use of bruker biotyper matrix-assisted laser desorption ionization time of flight mass spectrometry J Clin Microbiol. 2011;49(8):2868-73. https://doi. org/10.1128/JCM.00506-11

PMid:21613431

9. Anas M, Zinedine BA, Rizk HA, Eddine HJ, Mebrouk K Screening of autochthonous Lactobacillus species from Algerian raw goats' milk for the production of bacteriocin-like compounds against Staphylococcus aureus. Afr J Biotechnol. 
2012;11(20):4595-607.

10. Nilova LY, Orishak EA, Boitsov AG. Regarding the problem of probiotics usage for intestinal disbacteriosis therapy. Sci J Prevent Clin Med. 2010;2(35):70-7.

11. Haukioja A, Yli-Knuuttila $\mathrm{H}$, Loimaranta $\mathrm{V}$, Kari $\mathrm{K}$, Ouwehand AC, Meurman $\mathrm{JH}$, et al. Oral adhesion and survival of probiotic and other lactobacilli and bifidobacteria in vitro. Oral Microbiol Immunol. 2006;21(5):326-32. https://doi. org/10.1111/j.1399-302X.2006.00299.x

PMid:16922933

12. Russian Federation. General Pharmacopoeia Monograph (GPM).1.7.2.0012.15 Industrial Probiotic Strains and Strains for Probiotic Control; 2015. p. 49

13. Kabanikhin S, Krivorotko O, Takuadina A, Andornaya D, Zhang S. Geo-information system of tuberculosis spread based on inversion and prediction. J Inver III Posed Probl. 2021;29(1):65-79. https://doi.org/10.1515/jiip-2020-0022

14. Kintonova A, Ye N, Arynova Z, Kussepova L, Karymsakova A, Takuadina A, et al. Automation of business processes at the enterprise during a brand formation. Ad Alta. 2019;9(1):107-13.

15. Zheng J, Wittouck S, Salvetti E, Franz CM, Harris HMB, Mattarelli $\mathrm{P}$, et al. A taxonomic note on the genus Lactobacillus: Description of 23 novel genera, emended description of the genus Lactobacillus Beijerinck 1901, and union of Lactobacillaceae and Leuconostocaceae. Int J Syst Evol Microbiol. 2020;70(2):2782858. https://doi.org/10.1099/ijsem.0.004107 PMid:32293557

16. Kanak EK, Yilmaz SÖ. Maldi-tof mass spectrometry for the identification and detection of antimicrobial activity of lactic acid bacteria isolated from local cheeses. J Food Sci Technol. 2019;39(2):462-69. https://doi.org/10.1590/fst.19418

17. Pavlovic M, Huber I, Konrad R, Busch U. Application of MALDI-TOF MS for the identification of food borne bacteria. Open Microbiol J. 2013;7(1):135-41. https://doi. org/10.2174/1874285801307010135

PMid:24358065

18. Coman MM, Verdenelli MC, Cecchini C, Silvi S, Orpianesi C, Boyko $\mathrm{N}$, et al. In vitro evaluation of antimicrobial activity of Lactobacillus rhamnosus IMC $501^{(\circledR)}$, Lactobacillus paracasei IMC $502^{(囚)}$ and SYNBIO ${ }^{(囚)}$ against pathogens. J Appl Microbiol. 2014;117(2):518-27. https://doi.org/10.1111/jam.12544 PMid:24836638

19. Miladi H, Zmantar T, Chaabouni $Y$, Fedhila K, Bakhrouf A, Mandouani $\mathrm{K}$, et al. Antibacterial and efflux pump inhibitors of thymol and carvacrol against food-borne pathogens. Microb Pathog. 2016;99:95-100. https://doi.org/10.1016/j. micpath.2016.08.008 PMid:27521228

20. Kumar M, Dhaka P, Vijay D, Vergis J, Mohan V, Kumar A, et al. Antimicrobial effects of Lactobacillus plantarum and Lactobacillus acidophilus against multidrug-resistant enteroaggregative Escherichia coli. Int J Antimicrob Agents. 2016;48(3):265-70. https://doi.org/10.1016/j.ijantimicag.2016.05.014 PMid:27451088

21. Kang MS, Lim HS, Oh JS, Lim YJ, Wuertz-Kozak K, Harro JM, et al. Antimicrobial activity of Lactobacillus salivarius and Lactobacillus fermentum against Staphylococcus aureus. Pathog Dis. 2017;75(2):1-9. https://doi.org/10.1093/femspd/ ftx009

PMid:28158586

22. Muhammad Z, Ramzan R, Abdelazez A, Amjad A, Afzaal M, Zhang S, et al. Assessment of the Antimicrobial Potentiality and Functionality of Lactobacillus plantarum Strains Isolated from the Conventional Inner Mongolian Fermented Cheese Against Foodborne Pathogens» Pathogens. 2019; 8(2): 71. https:// dx.doi.org/10.3390\%2Fpathogens8020071

23. Silvaa DR, Sardib JC, Pitanguic NS, Roquee SM, Silva AC Rosalenad PL. Probiotics as an alternative antimicrobial therapy: Current reality and future directions. J Funct Foods. 2020;73:104080. https://doi.org/10.1016/j.jff.2020.104080

24. Kivanç M, Yilmaz M, Çakir E. Isolation and identification of lactic acid bacteria from boza, and their microbial activity against several reporter strains. Turk J Biol. 2011;35(3):313-24. https:// doi.org/10.3906/biy-0906-67

25. Duary RK, Rajput YS, Batish VK, Grover S. Assessing the adhesion of putative indigenous probiotic lactobacilli to human colonic epithelial cells. Ind J Med Res. 2011;134(5):664-71. https://doi.org/10.4103/0971-5916.90992

PMid:22199106

26. Collado MC, Surono I, Meriluoto J, Salminen S. Indigenous dadih lactic acid bacteria: cell-surface properties and interactions with pathogens. J Food Sci. 2007;72(3):M89-93. https://doi. org/10.1111/j.1750-3841.2007.00294.x

PMid:17995806

27. Stoianova LG, Ustiugova E, Netrusov Al. Antibacterial metabolites of lactic acid bacteria: Their diversity and properties. Prikl Biokhim Mikrobiol. 2012;48(3):259-75.

PMid:22834296

28. Prabhurajeshwar C, Chandrakanth RK. Probiotic potential of lactobacilli with antagonistic activity against pathogenic strains: An in vitro validation for the production of inhibitory substances. Biomed J 2017;40(5):270-83. https://doi.org/10.1016/j. bj.2017.06.008

PMid:29179882

29. Jose NM, Bunt CR, McDowell A, Chiu JZ, Hussain MA. Short communication: A study of Lactobacillus isolates' adherence to and influence on membrane integrity of human Caco-2 cells. J. Dairy Sci. 2017;100(10):7891-96. https://doi.org/10.3168/ jds.2017-12912

30. Lebeer S, Claes I, Tytgat HL, Verhoeven TL, Marien E, von Ossowski I, et al. Functional analysis of Lactobacillus rhamnosus GG pili in relation to adhesion and immunomodulatory interactions with intestinal epithelial cells. Appl Environ Microbiol. 2012;78(1):185-93. https://dx.doi. org/10.1128\%2FAEM.06192-11 PMid:22020518

31. Tuo Y, Yu H, Ai L, Wu Z, Guo B, Chen W. Aggregation and adhesion properties of 22 Lactobacillus strains. J Dairy Sci. 2013;96(7):4252-7. https://doi.org/10.3168/jds.2013-6547 PMid:23664349 